\title{
El arte y lo sagrado. Su encarnación en la Capilla Rothko
}

\author{
Sara BLANCO \\ Universidad de Granada \\ sarablancoq@gmail.com
}

\section{RESUMEN}

El presente artículo analiza la relación entre el arte y lo sagrado desde una doble perspectiva: teórica y artística. Desde el plano teórico, basados en las teorías de Gadamer y Eliade, encontramos en el símbolo el nexo entre el arte y lo sagrado. Desarrollaremos la naturaleza del símbolo según la teoría de Ricoeur. Desde la obra artística analizaremos la expresión de lo sagrado propuesta por Rothko en la Capilla Rothko en Houston (Texas, U.S.A.). Terminamos considerando el concepto de verdad en el símbolo artístico.

Palabras clave: Sagrado, arte, símbolo artístico, Rothko, Capilla Rothko.

\author{
Art and the Sacred. Its embodiment \\ in the Rothko Chapel
}

\begin{abstract}
The present article analyzes the relationship between art and sacred forms from the double perspective of theory and artistic forms. In the theoretical domain, based on the theories of Gadamer and Eliade, we find in the symbol the relationship between art and sacred forms. We develop the nature of symbols according to the theory of Ricoeur. In the artistic domain we analyze sacred expressions introduced by Rothko in the Rothko Chapel in Houston (Texas, U.S.A.). We conclude by considering the concept of truth in artistic symbols.
\end{abstract}

Keywords: Sacred, art, artistic symbol, Rothko, Rothko Chapel

SUMARIO: 1. Introducción. 2. Naturaleza del arte. 3. Naturaleza de lo sagrado. 4. El símbolo. 5. Capilla Rothko: encarnación de lo sagrado. 6. Inspiración de Rothko. 7. La verdad artística. 8. Conclusión. 9. Bibliografía. 


\section{INTRODUCCIÓN}

La belleza provoca en nosotros sentimientos asociados con lo trascendente. Tanto en la obra de arte como en la experiencia religiosa, el ser humano confronta aquello que considera real. Así como la experiencia religiosa tiene como resultado una elevada consciencia de lo que verdaderamente es y la disposición a dejarlo ser, la experiencia estética conduce a una nueva percepción ontológica.

No queremos mediante el presente artículo equiparar la esencia del arte con la esencia de la religión pues son únicas e intransferibles. Pretendemos, a pesar de su individualidad, discernir un nexo esencial entre el Arte y lo Sagrado.

Nuestro planteamiento nace del diálogo entre la reflexión teórica y la reflexión que genera la obra de arte proponiendo una retroalimentación entre ambas disciplinas. Después de un acercamiento teórico entre el arte y lo sagrado conoceremos como se representa lo sagrado en el arte contemporáneo a través del análisis de una de las obras más reconocidas del s. XX: la Capilla Rothko en Houston (Texas, U.S.A.).

Mark Rothko (1903-1970) forma parte de una generación de artistas norteamericanos que transformaron la expresión y comprensión de como se entendía hasta entonces la pintura. Esta visión revolucionaria se materializa en la evolución estilística de lo figurativo a un leguaje visual abstracto. Rothko a menudo negaba pertenecer a la escuela de Nueva York y le disgustaba que lo clasificaran como colorista o abstracto. Lo que realmente le interesaba era expresar las emociones humanas más elementales entablando una relación activa entre espectador y pintura. Transmitir a través del color y de la forma la misma experiencia religiosa que él sintió al pintarlo.

Al final de su vida sus cuadros son de tonalidades oscuras, con abundancia de marrones, violetas, granates y, sobre todo, negros. Corresponde a esta época la capilla encargada por John y Dominique de Menil, en Houston (Texas, U.S.A.). Un espacio de oración donde catorce cuadros cubren un espacio octogonal.

\section{NATURALEZA DEL ARTE}

Nos acercaremos a la naturaleza del arte desde la perspectiva de Gadamer que destaca por la renovación que supuso su obra en el campo de la hermenéutica. Su filosofía se fundamenta en la experiencia estética donde, según Gadamer, se produce una disolución entre el espectador y el objeto, esto es, la obra de arte. Experiencia que perseguía Rothko en sus pinturas, como muestra la siguiente cita:

No importa cuántas observaciones se hagan, nunca podrán explicar nuestras pinturas. Su interpretación debe surgir de una profunda vivencia entre cuadro y espectador. La valoración del arte representa una auténtica unión de sentidos. Y, como en un matrimonio, también en el arte la no consumación es motivo de anulación ${ }^{1}$.

\footnotetext{
1 Baal-Teshuva 2006, 7.
} 
Gadamer, ${ }^{2}$ basándose en Kant, explica la naturaleza del arte a través de la suma de tres conceptos: juego, símbolo y fiesta.

El juego y el arte son funciones básicas de la vida humana ya que no existe civilización que carezca de juegos ni de expresiones artísticas. El juego representa su propio movimiento, evidencia que es algo vivo y donde radica su propia esencia. Lo denominamos automovimiento. Como anotábamos anteriormente, Kant es el precursor de la autorreferencia del arte. La validación artística se origina en su propia autoexpresión. Las normas del juego, el uso de estrategia o el desvelamiento de aquello que muestra la obra, evidencia el uso de la razón como característica. Razón que genera conocimiento de la experiencia. No olvidamos su cualidad comunicativa, el jugar-con. No existe diferencia entre el jugador y el espectador. Ambos forman parte de un mismo evento en el que participan. Algo parecido ocurre entre la obra, el artista y el espectador.

En cuanto al símbolo, empezaremos con la definición de lo simbólico propuesta por Goethe y Schiller: ser remitido a lo indeterminado. Esto nos lleva al primer concepto de símbolo, donde el anfitrión le regalaba a su huésped una de las partes de una tablilla, la llamada tessera hospitalis. Esta tablilla se rompía en dos partes, conservando una mitad para sí y regalándole la otra mitad al huésped con el fin de reconocerse mutuamente juntando los dos pedazos si volvía a su casa un descendiente de ese huésped. Esta parábola de encuentro de almas puede ejemplificar lo que acontece en el arte. La obra remite a algo que no está de modo inmediato en la visión comprensible. Un fragmento concreta las cualidades de un todo universal.

El símbolo es «aquello en lo que se reconoce algo» ${ }^{3}$. Re-conocer significa conocer algo que ya se conoce, capta la permanencia de lo que ya no está. Y entender su sentido se convierte, no en imprescindible, pero sí en deseable comunicación. El significado del arte tal como lo entendieron Goethe y Schiller se concreta en hacer presente al referente al que remite. La representación simbólica no es dependiente de algo anterior. El medio que utiliza para su representación nos hace demorarnos en él, y reconocerlo.

El arte es un medio de conocimiento y de revelación. Los grandes, los creadores verdaderos, no pueden ser otros sino aquellos que en cualquiera de las artes hayan logrado revelar algo ${ }^{4}$.

Por último nos adentramos en el concepto de fiesta, que comparte con el arte el concepto de comunión y tiempo. La fiesta como la obra artística es comunidad: nos reúne, nos mezcla y fusiona. Toda fiesta que se celebre es una actividad intencional. La celebración no es una meta a la que llegar sino una incursión en otro tiempo en el eterno presente. El orden del tiempo se origina en la celebración de las fiestas. El

\footnotetext{
2 Reflejo la síntesis de los puntos principales de la obra de Gadamer 1991, 66-104.

3 Gadamer 1991, 113.

4 Zambrano 1989, 139.
} 
calendario, como forma de organización del tiempo, lo estructura como tiempo lleno y tiempo vacío. Al llenarlo, el tiempo se vuelve festivo y conectamos directamente con el carácter de la celebración. El arte ofrece tiempo, lo detiene. Nos invita a demorarnos. Ésta es la esencia de la celebración.

\section{NATURALEZA DE LO SAGRADO}

Nos acercamos a la naturaleza de lo sagrado desde la perspectiva desarrollada por Eliade, considerado uno de los fundadores del estudio moderno de las religiones. El autor situó lo sagrado en el centro mismo de la experiencia religiosa, como la experiencia primordial del Homo religiosus.

Lo sagrado y lo profano constituyen dos modalidades de estar en el mundo. Para Eliade, lo sagrado está relacionado con la verdad, con el origen, con la creación de la vida y lo real. Citamos sus palabras:

Lo sagrado es lo real por excelencia, y a la vez potencia, eficacia, fuente de vida y fecundidad. El deseo del hombre de vivir en lo sagrado equivale, de hecho, a su afán de situarse en la realidad objetiva, de no dejarse paralizar por la realidad sin fin de las experiencias puramente subjetivas, de vivir en un mundo real y eficiente y no en una ilusión 5 .

A través de la hierofanía, Eliade describe la manifestación de lo trascendente en un objeto o experiencia de nuestro cosmos habitual. El término nace de la palabra hieros: sagrado y phainomai: manifestarse. En la hierofanía se presenta una realidad diferente a través de objetos cotidianos como pueden ser las piedras, los animales o los humanos. Estos seres vivos o inertes no son adorados como tales; lo son precisamente por el hecho de ser hierofanías, por el hecho de mostrar algo que ya no es piedra ni árbol, sino lo sobrenatural, lo sagrado, lo completamente diferente, lo paradójico.

[...] toda hierofanía está constituida por una paradoja, incluso la más simple. Al manifestar lo sagrado, el objeto posee una doble naturaleza; se convierte en otra cosa sin dejar de ser él mismo, pues continúa participando del medio cósmico circundante,... su realidad inmediata se trasmuta en realidad sobrenatural ${ }^{6}$.

Una vez realizada esta incursión a la naturaleza de la obra artística y a la naturaleza de lo sagrado, entendemos que la naturaleza de la hierofanía comparte algunos puntos con la naturaleza de la obra de arte descrita por Gadamer. Tanto obra como hierofanía remiten a otra cosa más allá de sí mismas, entablan una relación con el

\footnotetext{
${ }^{5}$ Eliade 1998, 26.

${ }^{6}$ Eliade 1998, 15.
} 
espectador, son poseedoras de una naturaleza simbólica y proponen con su presencia una nueva configuración del espacio y un nuevo concepto del tiempo: aprender a demorarse.

Resumiendo, el núcleo que comparten hierofanía y obra artística es una naturaleza simbólica. Son poseedores de una doble naturaleza: la materia y lo que representa. Por ello, vamos adentrarnos en el símbolo. Su destino es el de revelar una realidad inaccesible a los demás medios de conocimiento. Esta realidad a la que hace referencia no es accesible a la experiencia inmediata del hombre ni al pensar discursivo.

\section{EL SÍMBOLO}

El simbolismo no se refiere únicamente a las realidades espirituales. En el pensamiento arcaico no hay separación entre lo espiritual y lo material. Ambos son complementarios y una realidad no implica la omisión de la otra. El significado literal no anula las implicaciones simbólicas y viceversa. Es muy clarificador el ejemplo puesto por Eliade:

Las asociaciones simbólicas no anulan el valor concreto y específico de un objeto o de una operación; ejemplo de ello tenemos en ciertas lenguas austroasiáticas aun cuando la azada se denomine falo y la siembra se asimile al acto sexual. Ello no implica que el agricultor primitivo ignore la función específica de su trabajo y el valor concreto, inmediato, de su instrumento ${ }^{7}$.

El simbolismo añade nuevas significaciones al objeto o a la acción sin negar la realidad primaria, más directa. La función esencial del símbolo es dar presencia a lo ausente. Sincroniza la experiencia histórica con el presente. Experimenta la finitud del hombre frente a lo trascendente. Para conocer la estructura del símbolo nos acercaremos a la teoría de Ricoeur, filósofo y antropólogo francés conocido por su intento de combinar la descripción fenomenológica con la interpretación hermenéutica. El autor afirma la existencia de una triple naturaleza siempre presente en el símbolo auténtico: la dimensión cósmica, la dimensión onírica y la dimensión poética. Sólo accediendo a estas tres dimensiones podremos comprender la capacidad reflexiva del símbolo.

Ricoeur señala los sueños como el lugar donde podemos observar el paso de la función cósmica a la función psíquica de los símbolos fundamentales. El símbolo es el lazo que une al hombre con el Ser Total. Esta aseveración no diferencia entre las hierofanías religiosas y las producciones oníricas interpretadas por Freud y Jung. Freud postuló que las producciones oníricas, más allá de la historia individual, se fundamentan en las representaciones básicas comunes a una cultura. La manera en

\footnotetext{
7 Eliade 1992, 191.
} 
que Ricoeur interpreta la regresión es con el proceso propio de la progresión y la exploración de nuestras capacidades. Tanto esta reinversión en nuestro organismo como las hierofanías, se realizan a través de un camino de símbolos. El cosmos y la psique son dos lugares donde se manifiesta lo sagrado. Al sumergirnos en el arcaísmo de la humanidad se produce una doble regresión: «Yo me autoexpreso al expresar el mundo» y «Yo exploro mi propia 'sacralidad' al intentar descifrar el mundo» ${ }^{8}$.

Nosotros creemos que Rothko sitúa lo transcendente en esa dualidad cósmica y psíquica donde las progresiones se materializan en las proyecciones del inconsciente del espectador. Para ello hacemos referencia a lo dicho por el artista en una entrevista realizada por Katherine Kuh el 14 de junio de 1954:

Y, si he de depositar mi confianza en algún sitio, la otorgaría a la psique del observador sensible y libre de las convenciones del entendimiento. No tendría ninguna aprensión respecto al uso que este observador pudiera hacer de estas pinturas al servicio de las necesidades de su propio espíritu: porque, si hay necesidad y espíritu al mismo tiempo, seguro que habrá una auténtica transacción? 9

Ahora bien, esta doble dimensión del símbolo -cósmica y psíquica- se complementa en una nueva característica: la imaginación poética ${ }^{10}$. Para entenderla tendremos que comenzar diferenciando entre imagen e imaginación. Ricoeur relaciona la imagen con la función de la ausencia, la reabsorción de lo real en un irreal figurado. La imagen es un procedimiento para hacerse presente, para representar las cosas en el mundo.

La imagen poética guarda más relación con la palabra que con la imagen. Con gran destreza lo expresa Bacherlard en La poétique de l'Espace, la imagen poética «nos transporta al manantial del ser parlante», «se convierte en un ser nuevo de nuestro lenguaje y nos expresa haciéndonos ser lo mismo que ella expresa». El símbolo poético nos presenta la expresividad en su estado naciente.

Rothko vacía sus cuadros. Crea un nuevo lenguaje en el que el icono desaparece y deja espacio al color para llevarnos a ese origen donde obra y espectador se fusionan.

Es como si se inventara un nuevo lenguaje de sonidos, donde el significante lo aporta cada inconsciente siendo inspirado por el tono y el ritmo de esas sílabas, que se materializa en formas y color.

¿Podemos decir que el símbolo ha desaparecido? Pensamos que no, pues color y forma siguen cumpliendo la función de símbolo al inspirar al inconsciente a través de la experiencia de la obra. El color y forma constituyen el nuevo lenguaje y en ello reside su necesidad de comunicar. Recordemos que cuando parte del lenguaje desaparece, los elementos que permanecen adquieren una fuerza renovada ${ }^{11}$.

\footnotetext{
${ }^{8}$ Ricoeur 1982, 175.

${ }^{9}$ Entrevista a Mark Rothko por Katherine Kuh, en Wick, Weiss, [et al], 2000, 171.

10 Ricoeur 1982,177.

11 Dupré 1999, 105.
} 


\section{CAPILLA ROTHKO: ENCARNACIÓN DE LO SAGRADO}

John y Dominique de Menil encargaron a Rothko a principios de 1965 varios murales de gran formato concebidos para una capilla que planeaban construir en St. Thomas Catholic University (Houston, U.S.A.), donde Dominique dirigía el Departamento de Arte. Finalmente se autorizó a Rothko a intervenir en los planos del edificio determinando el entorno arquitectónico y la iluminación de las pinturas. Eso supuso una nueva forma de creación no conocida hasta entonces basada en la interrelación entre las pinturas, la arquitectura y la luz ${ }^{12}$.

Rothko propuso una planta octogonal, similar a un baptisterio, de modo que las pinturas rodearan al visitante. La estructura octogonal debía responder al equilibrio entre la tensión axial y la coherencia de un cuerpo compacto. La construcción del edificio era de líneas sencillas para otorgar mayor protagonismo a las pinturas.

From the beginning he had wanted an octagonal interior, balancing the right mixture of axial tensions and coherent compactness, combining a multiplicity of obliquely angled walls with ready surveyability, and keeping the architectural surround itself restrained and uncompetitive ${ }^{13}$.

El contraste entre el interior y exterior de la capilla es una metáfora de la realidad interior y exterior, entre el mundo visible de los sentidos y la realidad que es revelada por el ojo del intelecto.

En contraposición a la capilla de Matisse (Vence, Francia), que persigue la ligereza y la luz y de la que repetidamente se ha dicho que el artista tomó como modelo, Rothko presenta su antítesis: una caverna de luz negra. En su interior catorce pinturas de colores oscuros están distribuidas en ocho módulos asignadas a las ocho paredes que conforman la capilla. A su vez estas catorce pinturas se dividen en dos grupos: siete pinturas con un rectángulo negro opaco de contornos nítidos y otras siete monocromas con un efecto más orgánico y seductor, sugiriendo un contraste formal y una equivalencia entre los dos grupos. En la capilla sin ventanas, los oscuros murales están cargados de melancolía y soledad, soledad que confronta al espectador consigo mismo, con la nada que emerge de la oscuridad. Y donde, poco a poco, la visión de las profundidades empieza a transformarse en color, luz, contraste, transparencia, opacidad y espacio, que van emergiendo de esa nada.

Nodelman describe su experiencia en la capilla Rothko como la superposición de tres experiencias diferentes que no son progresivas en el tiempo sino que interaccionan y se solapan unas a otras indistintamente. Pasamos a describirlas. La primera sensación que siente el espectador al entrar a la capilla es de desconcierto por no estar familiarizado con el aparato discursivo que la experiencia de la capilla ofrece. No es

\footnotetext{
12 Quién quiera profundizar en el estudio sobre esta interrelación remitimos a la magnífica obra de. S. Nodelman, The Rothko Chapel Paintings. Origins, Structure, Meaning, Austin, 1997.

13 Nodelman 1997, 74.
} 
sólo que las pinturas no sean icónicas sino que difícilmente se encuentran elementos normalmente presentes en las pinturas abstractas como gestos expresivos, rico cromatismo, contraste tonal, etc. Las pinturas más que activar nuestra imaginación empujan al frustrado espectador hacia sí mismo ${ }^{14}$. El espectador rodeado de los imponentes y sobrios cuadros no tiene escapatoria.

La gran escala utilizada en las pinturas genera una doble sensación en el cuerpo del espectador atendiendo a la totalidad de la obra y a su división en módulos. El espectador se siente intimidado por la contundente unidad de la obra pero paralelamente al estar las pinturas divididas en módulos propicia la proyección del espectador en las mismas generando una expansión del yo. Este recurso, propio de la monumentalidad clásica, Rothko lo llevó a su máxima expresión.

En relación a la apariencia formal de las pinturas con rectángulo negro y a las monocromas existe una relación macro- micro compositiva. Los rectángulos negros son demasiado grandes en comparación al cuerpo del espectador y las formas orgánicas de las pinturas monocromas son demasiado pequeñas con respecto a la figura humana y a la composición a la que pertenece, desapareciendo su figura en un extenso campo de color. Poco a poco estas formas van emergiendo siendo los únicos vehículos para la identificación imaginativa. Lo que sugiere Nodelman es que estas dos reacciones de proyección y retraimiento responden a la escala de lo sublime, que no es fácil describir.

The distinctive scale experience of the chapel installation results from the superimposition of these two scale regimes, the classical-monumental and the romantic-sublime, and thus from both the radical affirmation of the existential specificity of the subject and its dissolution into the universal ${ }^{15}$.

Otra característica de la capilla es su instalación cíclica que está estructurada en forma de espejo. No tiene principio ni final y por lo tanto no tiene una línea narrativa. Nos presenta el tiempo ontológico.

El segundo tipo de experiencia que genera la observación de la capilla es tratar de analizar los elementos que nos presenta la instalación. Nos damos cuenta que la estructura octogonal esta formada por cuatro paredes más grandes que están orientadas a los puntos cardinales. La pared sur (acceso) presenta una única pintura con rectángulo negro opuesto al tríptico de monocromos en el ábside frontal (norte). Nodelman sugiere la lectura de lo Uno frente a la Multiplicidad, lo cerrado frente a la abertura, el fin frente al futuro, etc. Dominique de Menil relata que la intención expresada por Rothko era recrear esta misma tensión que existe en la iglesia de Torcello, el juicio final en la entrada frente al glorioso ábside ${ }^{16}$. Estos módulos representan la tensión del eje principal que a su vez comparten un sustrato común.

\footnotetext{
14 Nodelman 1997, 297

${ }^{15}$ Nodelman 1997, 301

${ }^{16}$ De Menil 2010, 18.
} 
En las otras dos paredes laterales del cuadrángulo se encuentran dos trípticos con figura negra en su interior que se expande hasta los bordes del cuadro creando un marco que resulta claustrofóbico e inquietamente inestable. En las cuatro paredes de los ángulos restantes oblicuamente colocadas al eje principal cuelgan pinturas monocromas que aportan una lectura unitaria y rotacional a la capilla. Estas pinturas contribuyen a la unidad y continuidad, exactamente lo opuesto que genera la pintura de la pared sur (acceso) con el ábside frontal (norte). La relativa debilidad de las pinturas monocromas y la ilimitada expansión de sus campos de color generan un suelo interno de repetición y recurrencia solo interrumpido por las pinturas del eje principal.

Debido a la forma octogonal de la capilla, el esquema cuadrilátero establecido por las paredes principales está inscrito dentro de un circuito más inclusivo de ocho paredes rotacionales, encerrando la oposición dentro de una larga continuidad. La conjunción entre lo finito y lo infinito.

La simbología de los colores utilizados también afirma esta teoría. Si bien el negro ha sido en la cultura occidental asociado con la muerte, el rojo simboliza el significado opuesto: la vida. Los colores rojizos son utilizados en los cuadros monocromos, asociado con la idea del absoluto mientras que el negro es la forma de los rectángulos opacos se relaciona con lo relativo y en el dominio de la mortalidad ${ }^{17}$. El tono azul, asociado culturalmente al cielo, aparece implícitamente mezclado con el rojo haciendo una variación hacia el violeta.

The deep brownish and purplish red had appeared already in large canvases painted in 1958 and 1959. From this time on, it became his basic and recurrent color, the color elected to bring his paintings to their maximum of poignancy, as he said. As he worked on the Chapel, which was to be the greatest adventure of his life, his colors became darker and darker, as if he were bringing us the threshold of transcendence, the mystery of the cosmos, the tragic mystery of our perishable condition. The silence of God, the unbearable silence of God ${ }^{18}$.

El tercer tipo de sensación que genera la instalación es cuando la capilla pasa de ser concebida como objeto a ser concebida como acontecimiento. El atento observador se dará cuenta del efecto de distracción que tiene la presencia de otros espectadores en su experiencia con la instalación. La relación entre espectador y actor se invierte. Observas y eres observado recordando al teatro panóptico de Michel Foucault. Esto pone a prueba las propias psicodinámicas de subjetividad del espectador ${ }^{19}$ llevando a una nueva polaridad entre el observador y el objeto observado.

La estructura «objetiva» de la instalación revela un incesante contraste entre opuestos y un intenso autoescrutinio que emerge del espectador al ser conciente de

\footnotetext{
17 Nodelman 1997,324.

18 De Menil 2010, 22.

19 Nodelman 1997, 331.
} 
este proceso sin fin en el que el observador se ha involucrado. No se puede parar en ningún punto o conclusión. Te encuentras en tu propio laberinto buscando al doble imaginario.

The chapel installation can thought of as an experimental demonstration of this Kierkegaardian- Nietzschian conception applied to the psychodynamics of pictorial spectatorship. Repetition an recurrence as they occur in the installation in their different ways consist in the re- presentation of the «same» ${ }^{20}$.

Rothko no pretendía con esta obra una fácil o consoladora experiencia. Por su propia iniciativa se había propuesto crear pinturas a las que «no quisieras mirar».

Las pinturas negras son, en cierto modo, la absorción de todo un proceso creativo anterior que se fundamenta en el análisis de la luz. Según Argullol, en el extraordinario artículo publicado en el catálogo de la Fundación Miró, la obra de Rothko se adivinan dos constantes: el despojamiento y la liberación de la luz que, o bien se pueden plasmar a través de composiciones con colores luminosos o en espacios oscuros y monocromos que derrochan luz propia, haciendo alusión a las dos etapas marcadas del artista. En este juego de luces y sombras opera una tensión entre lo visible y lo invisible, la presencia y la ausencia, dentro de un contexto escatológico. En esta tensión de opuestos estriba el significado.

El elemento negativo dentro del símbolo religioso es de gran importancia, a diferencia del símbolo estético, el cual posee una revelación directa de su significado. Los auténticos símbolos religiosos expresan la realidad a la que remiten gracias a la paradoja, su racionalización es posterior. El origen de lo que ahora llamamos símbolos religiosos responde a los primeros intentos por enunciar la realidad. Estos no crean realidades opuestas, sino que encuentran su definición en su opuesto, integrando los niveles de realidad que oponen. Su estructura es mucho más compleja que los conceptos racionales.

En esa paradoja, la obra de Rothko se debatía entre la belleza formal y el contenido espiritual que atribuía a la obra.

[...] como ha recordado James E.B. Breslin, si alguien ponderaba la belleza sensual de sus cuadros, Rothko aludía a su aspecto espiritual, pero si se insistía en la espiritualidad, entonces se definía a sí mismo como un materialista terrenal ${ }^{21}$.

Lo que nos llama más la atención es como un arte no específicamente religioso provee de significado a una capilla, espacio dedicado al culto. Pensamos que puede ser debido a dos razones. La primera como consecuencia del fenómeno de la secularización en relación a la transformación de lo sagrado en el s. XX. Los discursos religiosos muestran un cansancio en la repetición de sus símbolos, por lo que grandes

\footnotetext{
${ }^{20}$ Nodeman 1997, 337.

21 Wick, Weiss, [et al.] 2000, 187.
} 
instituciones religiosas piden a artistas que no forman parte de sus confesiones que, desde sus nuevos lenguajes plásticos, llenen esos espacios con la emotividad y espiritualidad que producen sus obras. Este proceso de creación artística implica el sacrificio del lenguaje religioso como el primer paso para liberar y contener el misterio de lo sagrado. Eliminar aquello que por su uso ha quedado desposeído de significado y presentarlo de una forma nueva y fresca. La segunda razón es debido a la naturaleza del acto religioso, que afirma una realidad suprema. Las imágenes son tan poderosas en la simbolización religiosa como en la artística, pero cumplen diferente propósito. Mientras en el arte la imagen es la realidad artística, en la experiencia religiosa cumple una función subordinada y, en gran parte, negativa.

El hombre religioso recurre a las imágenes porque no puede expresar directamente lo que desea verbalizar y las imágenes le permiten escapar a una realidad dada. No obstante, no termina de atribuir una realidad definitiva a las imágenes.

Hegel $^{22}$ tenía una clara conciencia de la reacción negativa que genera la religión en contra de sus propias imágenes. El contenido religioso sólo puede ser percibido por la abstracción que eleva lo imaginario y lo sensible a un nivel universal, e implica el rechazo de la imagen. Según Hegel, la concordancia demasiado estrecha entre una religión y sus imágenes puede llevar a su extinción. Ejemplo de ello es la religión mitológica de la antigua Grecia, donde trasladaron los poderes naturales y mortales de la vida en formas estéticamente idealizada. En lugar de negar la existencia cotidiana, la embellecían. El aumento de su perfección finita derivó en una pérdida de significado como símbolo religioso. En este caso la religión permanece cautiva de sus propias imágenes estéticas y esta razón podría haber llevado a Rothko a vaciar sus cuadros.

La naturaleza de su lenguaje abstracto también puede responder a la creencia que tenían los pioneros de la abstracción -Kandinsky, Malevich y Mondrian- de que los principios y fuerzas que gobiernan el cosmos podían ser expresados de forma directa a través de la abstracción. Pensamiento que recoge Dominique de Menil: «We are cluttered with images, and only abstract art can bring us to the threshold of the divine ${ }^{23}$.

En esta apuesta de redecir lo sagrado queremos hacer mención a uno de los escritos de Rothko llamado Philosophies donde el artista compara a Dios con la abstracción al no poder acceder a ella de forma directa. Por otro lado, su naturaleza es tan grande que sólo nos acercaremos por una de sus representaciones, constituyendo una imagen limitada y no el Ser mismo.

Como sucede con la antigua idea de Dios, la abstracción misma en su desnudez no se puede aprehender nunca de manera directa. Como en el caso de Dios, sólo podemos conocer sus manifestaciones a través de las obras, que aun cuando nunca revelan completamente la abstracción en su conjunto, la simbolizan a través de la

22 Dupré 1999, 63-65. 
manifestación de sus diferentes rostros en la obra de arte. Por eso, sentir belleza es participar en la abstracción a través de un medio particular. En un sentido, se trata de una reflexión sobre la infinitud de la realidad. En el caso de que llegáramos a conocer la apariencia de la abstracción misma, estaríamos constantemente reproduciendo sólo su imagen. Lo que tenemos es la manifestación de la variedad infinita de sus rostros inagotables, por lo cual debemos estar agradecidos ${ }^{24}$.

Cuando Rothko escribió este texto, aproximadamente en los años 40, estaba pintando múltiples rostros de Dios. Para ese entonces todavía tenía fe en la figura humana como el modelo unitario de representación. La duda acerca de sus mediaciones le llevó a buscar una inmediatez entre pintura y observador. Como nos muestra el texto, Rothko era conocedor de los fundamentos teológicos según los cuales «a Dios se le conoce por medio de las distintas manifestaciones sensibles». Lo visible e invisible a través de la encarnación divina y sólo parcialmente a través de la creación, según la teología paulina. Quizá podemos arriesgarnos a decir que dejó a un lado la creación realista y abogó por representar lo visible y lo invisible. Por otro lado, no podemos conocer la abstracción desnuda de forma directa, sin velos, pero si lo intentamos, como propone Rothko, sólo estaremos repitiendo una y otra vez la misma imagen, la imagen esencial de la abstracción y a la que Rothko llamó Dios ${ }^{25}$.

El método escogido por Rothko en busca de esa abstracción fue semejante a la vía ascética del desprendimiento, para así llegar también desnudos nosotros ante la imagen desnuda de Dios. A pesar de ser grandes cuadros pueden ser al tiempo verdaderamente íntimos, pues allí se descubren los espacios interiores y ocultos. La profundidad de sus cuadros, en palabras de Vega Esquerra, es la experiencia de penetración en los estratos de las cosas cada vez más distantes, que inicia una actitud de abandono de sí mismo para penetrar en el espacio de la superficie que emerge de la tela.

Eliade, en su ensayo titulado Permanencia de lo sagrado en el arte contemporáneo $^{26}$, establece una relación de semejanza entre el artista existencial y el teólogo del s. XX. Así como el teólogo tuvo que asumir la muerte de Dios, el artista rechaza representar los ídolos. Esto no quiere decir que lo sagrado ha desaparecido, sino que está camuflado en formas, intenciones y significaciones aparentemente profanas. Lo sagrado ya no se encuentra en el lenguaje religioso convencional como ocurría en la Edad Media o la Contrarreforma. Por ello, para una hermenéutica completa, se hace imprescindible ahondar en el inconsciente, en la psicología profunda y en el análisis de Jung. Eliade confirma que lo sagrado se representa en dos tendencias: la destrucción de las formas tradicionales y la fascinación por lo informal, por modos elementales de la materia que son susceptibles de una interpretación religiosa.

\footnotetext{
24 Rothko 2006, 64-65 en. Vega Ezquerra 2010, 101.

25 Vega Ezquerra 2010, 102.

26 Eliade 2005, 139-146.
} 
Para Rothko, el único arte que conmovía es aquel que distorsiona, es decir, el arte que se fundamenta en la pérdida de una forma y se entrega a otra forma nueva y desconocida creando un movimiento que nos emociona, sacándonos y arrastrándonos fuera de nosotros mismos. Esta profundidad se puede traducir como conocimientos sensibles, ya que se descubren los velos de lo que estaba oculto. De esta forma, una dimensión metafísica ha descendido y se ha hecho próxima con el objetivo de tener una relación real con las cosas.

\section{INSPIRACIÓN DE ROTHKO}

Rothko, a pesar de ser un gran innovador formal dentro del campo de la pintura, demostró un gran interés por la espiritualidad que subyace en lo «universal y primordial» como expresó junto con Gottlieb en el escrito The Portrait and the Modern Artist en el programa de radio Art in New York, el 13 de Octubre de 1943:

Mientras el arte moderno consigue su primer ímpetu a través del descubrimiento de formas del arte primitivo, nosotros sentimos que su verdadero significado descansa no en los arreglos meramente formales, sino en el significado espiritual que subyace a todos los trabajos arcaicos ${ }^{27}$.

Nosotros compartimos la tesis de Dupré ${ }^{28}$ sobre el origen de los símbolos religiosos como descendientes directos de los símbolos primitivos. Los símbolos religiosos son de naturaleza paradójica, poco evidente y elusiva. Por este elemento negativo los filósofos han relacionado los símbolos religiosos con la imaginación, ya que esta facultad desconfía de la primera apariencia que muestra el objeto. A pesar haber otorgado la conciencia religiosa un mensaje claro a sus símbolos, estos siguen siendo polivalentes y permiten gracias a la imaginación añadir al significado establecido un nuevo universo de significados.

También existe una semejanza entre los símbolos del subconsciente y los símbolos religiosos. Las imágenes del subconsciente no son símbolos religiosos plenamente constituidos, necesitan de una intencionalidad religiosa explícita y consciente. Esta intencionalidad no explica el poder subconsciente del símbolo: sólo lo resalta y permite que ejerza su fuerza. Muchas de las imágenes y asociaciones oníricas nos remiten a mitos y ritos primitivos. Esto es lo que Freud llama remanentes arcaicos: «elementos psíquicos supervivientes en la mente humana desde lejanas edades» ${ }^{29}$. Estas imágenes hacen de vínculo entre dos mundos: el racional y el del instinto. Jung explica estas imágenes desde la emancipación de los sueños de las edades primitivas y fantasías creadoras que después fueron elaboradas cuidadosa y conscientemente en símbolos y conceptos.

\footnotetext{
${ }^{27}$ Stewart 1996, 80.

${ }^{28}$ Dupré $1999,58 \mathrm{~s}$.

29 Jung 1995, 47.
} 
Según el artista, lo que marcó la progresión de su estilo fue un crecimiento en la clarificación de su temática. El contenido de su obra fue fundamental. Rothko y Gottlieb enfatizaron esto el 13 junio de 1943 en una de sus famosas cartas al The New York Times, donde declaraban:

Es una idea ampliamente aceptada entre pintores que no importa lo que uno pinta siempre y cuando esté bien pintado. Esta es la esencia del academicismo. No existe tal cosa como una buena pintura sobre nada. Nosotros afirmamos que el tema es crucial.

Lo que a ellos les interesaba eran los mitos primitivos y símbolos que continuaban teniendo vigencia.

Hacia 1958, el mismo año que recibió el encargo de los murales para el restaurante Four Seasons en el Seagram Building (New York, U.S.A.), Rothko sintió la necesidad de refutar las críticas recibidas por lo que dio una charla en el Pratt Institute (New York, U.S.A) exponiendo que la dirección que había tomado su trabajo era una clara preocupación por la muerte, a lo que añadió «sólo el tema de este asunto es valido, el cual es trágico y atemporal».

La historia nos demuestra que la muerte siempre ha estado relacionada con lo sagrado, ya sea en el concepto de muerte, en la actitud demostrada hacia el difunto o bien las creencias de supervivencia ${ }^{30}$. Los documentos más antiguos encontrados tratan sobre la muerte, tema que siempre ha interesado al hombre. Esto muestra la necesidad del hombre de explicarse a sí mismo en que consiste la muerte y lo que puede haber detrás de ella y, también, que significa la vida. Estos escritos implican una creencia en lo sobrenatural.

Volviendo a la capilla de Rothko, los murales están cargados de melancolía y soledad. Para algunos es una invitación al infinito a través de esas tonalidades rojas y marrones, mientras que para otros esta relacionada con la muerte, viendo la capilla como un lugar de dolor y de luto. Hace sentir la estrechez del entorno y la densidad del tiempo, siendo el nacimiento y la muerte los únicos limites de la visión interior. En lo que sí estamos de acuerdo es en que la obra de Rothko tiene la voluntad de transcender. Son obras que nacen de la experiencia y reclaman ser reconocidas como verdad. Hacemos referencia a Weber en su libro Essays on Art:

Un color debe ser más que un color. Una forma debe ser más que una forma; debe sugerir lo sagrado que sólo se encuentra en lo espiritual. Todo debe ser más que lo que es visible ${ }^{31}$.

\footnotetext{
${ }^{30}$ Para una mayor profundización en esta temática remitimos al capitulo «Lo Sagrado y la Muerte» de Louis- Vicent Thomas en Ries (ed.) 1995, 215.

31 Clearwater 1984, 17.
} 
Según registró Ashton ${ }^{32}$ en una de sus entrevistas con Rothko, el artista mencionó en sus lecturas a los padres de la iglesia donde destacó entre las autoridades patrísticas a Origen, un cristiano gnóstico radical, cuya postura en el extremismo intelectual y el proto-existencialismo atraía a Rothko ${ }^{33}$. Su método de interpretación bíblica se caracterizaba por una búsqueda intensa y violenta de un sentido más alto detrás del significado literal del texto. Nodelman como resultado del análisis de la capilla llega a la conclusión que al menos Rothko debió de leer también a Agustín ${ }^{34}$, siendo el padre entre los autores patrísticos que más había desarrollado una visión sobre el arte. La obra de Rothko y los escritos de Agustín comparten una misma crítica sobre self-presentness y sobre el estatus de realidad de las cosas en la experiencia ordinaria. Además uno de los temas destacados de Agustín la identidad y la diferencia y la propia identidad y la recurrencia, como hemos visto, son expresados en la capilla. Nodelman basa sus sospechas de la inspiración de Rothko en los escritos de Agustín, concretamente en el planteamiento no del todo negativo que tiene acerca del carácter incompleto y el perpetuo aplazamiento al que están sometidas las cosas creadas, pues a partir de estas carencias surge la posibilidad del contraste, siendo la belleza sensible su resultado. La belleza del mundo se compone de su contrario. Como hemos analizado la estructura de la capilla se fundamenta en las relaciones de opuestos.

\section{LA VERDAD ARTÍSTICA}

Además de su cualidad transcendente hemos de reconocer su naturaleza artística. El símbolo artístico transforma lo significado. Destacamos y sintetizamos tres posturas (Goodman, Heidegger, Gadamer,) de las contenidas en el magnífico estudio realizado por García Leal acerca de la representación y la verdad ${ }^{35}$.

Goodman explica que al hecho de simbolizar se le atribuyen ya ciertos rasgos o propiedades. La simbolización artística construye y confecciona aquello que conoce, confiriéndole un significado. Esto nos lleva a preguntarnos: ¿ese significado tiene valor de verdad? ¿Podemos decir que la obra de Rothko es poseedora de verdad? Sólo cuando se defina la naturaleza de la verdad del arte, la estética estará legitimada para proclamar su verdad. A diferencia de otras ramas del conocimiento, el arte no posee una verdad enunciativa y eso ha hecho que algunos estetas dudaran de su veracidad. Ese es el caso de Goodman, que desacredita el conocimiento que se desprende de la obra artística por ser un conocimiento que no formula enunciados. Por ello los califica como conocimiento sin valor de verdad.

\footnotetext{
32 n. Orillynaly reported by Ashton in her account of her July 7, 1964, visit to Rothko in her Diary, entry for that day, cited in James Breslin, Mark Rothko: A Biography (Chicago and London,1993) 460,650 n.3; Dore Ashton, About Rothko (New York, 1983), 169, citado en Nodelman 1997, 355.

${ }^{33}$ Nodelman 1997, 290.

${ }^{34}$ Para un análisis más detallado entre el pensamiento de Agustín y la Capilla Rothko remitimos a Nodelman 1997, 290-293.

${ }^{35}$ García Leal 2002, 273-309.
} 
Heidegger, en cambio, mostró que la verdad del arte, más que procurar un sentido, proporciona un doble movimiento de descubrir (desocultar y revelar por un lado), y de ocultamiento y encubrimiento por otro. El autor demuestra que el concepto de aletheia (desocultamiento), conforma sólo una de las caras de la moneda indisoluble de su opuesto, el encubrimiento. Describe de la siguiente forma la verdad:

1. La verdad es inseparable de la no verdad. Ello no quiere decir que lo verdadero se confunda con lo falso y que por lo tanto la verdad procede de la no verdad.

2. La verdad es condición de acontecimiento.

3. La obra de arte demuestra que la verdad es lucha entre el mundo y la tierra. Lucha por imponer significación a unos materiales. Expone que «la obra de arte exhibe a través de la forma la lucha de la verdad y revela que la verdad es lucha».

La aletheia (desocultamiento), «la verdad de una obra», no puede contenerse en un enunciado, «no es contrastable con los hechos ni traducible a otro lenguaje». Su carácter parcial de la verdad, su procedimiento abierto y su perdurabilidad en el tiempo, derivan de la misma esencia de la verdad.

Heidegger no niega su relevancia pero restringe la verdad a las proposiciones. No atribuye el nominativo de verdad a la obra artística por no poder responder a la articulación binaria: verdadero/falso. La proposición es verdadera o falsa respecto a la cosa o al hecho del que se predica. El estado de descubrimiento carece de una referencia con la que medirse. Para Gadamer, en cambio, la verdad acontece en la representación. La obra transforma lo que representa. Genera una nueva interpretación donde muestra su esencia, su verdad. Por eso podemos decir que representación tiene un alcance ontológico. Adquiere una existencia original, la representación adquiere la existencia en la verdad.

La verdad no preexiste ni está en las cosas de por sí: acontece en un proceso ininterrumpido, renovándose siempre, y esto acontece en la representación. O en la simbolización, si nos atenemos a un término más abarcante ${ }^{36}$.

Lo esencial del arte es su capacidad de descubrimiento y anticipación, de prefigurar disposiciones para ver y perspectivas desde las que se mira,... porque a través del mundo instaurado por las obras de arte se abre un nuevo campo de sentido... dimana una luz que nos permite entender y resituarnos en nuestro mundo histórico ${ }^{37}$.

Nuestra postura se acerca más a la de Heidegger, pero lo vamos intentar explicar con términos relativos al lenguaje, menos abstractos. Esta cualidad de simbolizar que tiene la obra la vamos a comparar con la cualidad reveladora que tiene una metá-

\footnotetext{
36 García Leal 2002, 88.

37 García Leal 2002, 309.
} 
fora. La metáfora no podemos calificarla como verdadera o falsa en sí misma sino si expresa o oscurece lo que refiere. Por ello la aletheia para nosotros tendrá cualidad de conocimiento en la manera que revele algo que anteriormente estaba oculto, pero ese conocimiento será verdadero sólo si la cosmovisión a la que remite es verdadera y de igual forma en el caso contrario. Lo que analizamos en el campo del arte es la capacidad artística y técnica del artista de realizar una metáfora. Si el espectador quiere ir más allá y analizar la verdad de la cosmovisión a la que hace referencia ese desocultamiento, necesitaríamos adentrarnos en el campo de la filosofía moral.

\section{CONCLUSIÓN}

La obra de Rothko ha supuesto un antes y un después en el campo de la pintura. El artista desarrolla el lenguaje de la abstracción pictórica iniciado por Kandinsky a través de vaciar sus cuadros de contenido y proponiendo una experiencia entre obra y espectador. Por no querer influir en esa transacción, Rothko dejó de publicar acerca de sus intenciones artísticas y llegó a arrepentirse de haberlo hecho con anterioridad. Así lo expresó en 1954 en varias cartas a Katharine Kuh, que le había pedido que escribiera sobre sus objetivos e ideas artísticas con vistas a una futura publicación:

Desde el momento en que comencé a recopilar mis ideas, vi claramente que el problema aquí no radica en lo que se debería decir, sino en lo que yo puedo decir [...]. Perdone si continúo con mis recelos, pero me parece importante ponerlos encima de la mesa. Existe el peligro de que [...] creemos un instrumento que diga al público cómo debe mirar los cuadros y qué hay que buscar en ellos. Aunque, aparentemente, esto pudiera parecer obligado y necesario, el resultado final sería la parálisis de la mente y de la imaginación (y, para el artista, la sepultura prematura). Por ello, mi repulsión a los prólogos y a las explicaciones. Si tuviera que depositar mi confianza en algún sitio, lo haría en la psique del observador sensible, aquel cuyo entendimiento se encuentra libre de toda convención ${ }^{38}$.

Nosotros pensamos que todo símbolo necesita de una hermenéutica porque forma parte de su naturaleza. Rothko transformó el lenguaje de la pintura desposeyéndolo de contenido. Como hemos visto con anterioridad, su obra sigue siendo metáfora y provee, volviendo al ejemplo del lenguaje, de nuevos sonidos y ritmos, pero no ofrece el referente. Lo deja abierto, a la imaginación, a la experiencia de contraste y al subconsciente del espectador. Es como afirmar que nos presenta la nada o nos describe lo indescriptible. Como expresó el artista «No importa cuantas observaciones se hagan, nunca podrán explicar nuestra pinturas ${ }^{39}$.

\footnotetext{
38 Jimenez- Blanco "Rothko Jimenez Blanco", http://www.revistadelibros.com/articulo_imprimible_pdf. php?art=4342\&t=articulos, [25.09.2013].

39 Baal- Teshuva 2006, 7.
} 
Creemos que es en la psique del espectador donde Rothko sitúa la transcendencia entendiendo la psique y el cosmos como dos lugares donde se manifiesta una misma expresividad. La parte más profunda del ser humano, la espiritual-existencial es siempre inconsciente, porque el espíritu procede del inconsciente. Eso explicaría lo que tiene de necesaria e irreductible la espiritualidad. «El inconsciente no debe ser desdeñado; es tan natural como ilimitado, y tan poderoso como las estrellas» ${ }^{40}$.

\section{BIBLIOGRAFÍA}

J. Baal-Teshuva, Mark Rothko 1903-1970.Cuadros como dramas, Köln, 2006.

B. Clearwater, Mark Rothko. Works on Paper, New York, 1984.

D. De Menil, The Rothko Chapel. Writings of Art and the Threshold of the Divine, Houston, 2010.

L. Dupré, Simbolismo religioso, (trad. esp.), Barcelona, 1999.

M. Eliade, El vuelo mágico, (trad. esp.) Madrid, $2005^{4}$.

M. Eliade, Imágenes y símbolos, (trad. esp.) Madrid, 1992.

M. Eliade, Lo sagrado y lo profano, (trad. esp.) Barcelona, 1998.

H. G. Gadamer, La actualidad de lo bello. El arte como juego, símbolo y fiesta, (trad. esp.), Barcelona, 1991.

J. García Leal, Filosofia del arte, Madrid, 2002.

M. D. Jimenez- Blanco «Rothko Jimenez- Blanco», http://www.revistadelibros.com/articulo_ imprimible_pdf.php?art=4342\&t=articulos, [25.09.2013].

C. G. Jung, El hombre y sus simbolos, (trad. esp.), Barcelona, 1995.

S. Nodelman, The Rothko Chapel Paintings. Origins, Structure, Meaning, Austin, 1997.

P. Ricoeur, Finitud y Culpabilidad, (trad. esp.) Madrid, 1982.

J. Ries (ed), Tratado de antropología de lo sagrado [1]. Los orígenes de homo religiosus, Madrid, 1995.

M. Rothko, The Artist's Reality: Philosophies of Art, London, 2006.

Stewart, Tabori \& Chang Ed., Mark Rothko 1903-1970, Tate Gallery Publishing, London, 1996.

A. Vega Esquerra, Sacrificio y creación en la pintura de Rothko: la vía estética de la emoción religiosa. Madrid, 2010.

O. Wick, J. Weiss, [et al.] M. Rothko [catálogo exposición celebrada en noviembre 2000-enero 2001] Fundació Joan Miro, Barcelona, 2000.

M. Zambrano, Algunos lugares de la pintura, Madrid, 1989.

40 Jung 1995, 103. 